\title{
Os recursos para ir além e a mecânica do juízo: sobre o consumo de substâncias como prática cultural jovem nas festas de música eletrônica
}

\author{
Ivan Paolo de Paris Fontanari
}

\begin{abstract}
resumo Proponho-me, neste artigo, a analisar e interpretar o consumo de substâncias comumente referidas como "psicoativas", "psicotrópicas", "tóxicas", ou "entorpecentes", nas festas de música eletrônica (raves), como práticas culturais e identitárias de jovens de camadas médias, a partir de dados obtidos no trabalho de campo realizado na cena eletrônica de Porto Alegre. Objetivando o distanciamento em relação às construçóes produzidas pelo senso-comum sobre estas substâncias, procuro, através da descrição etnográfica, reconstruir alguns dos sentidos a elas atribuídos pelos próprios nativos no contexto local de apropriaçáo simbólica e consumo. Entre eles, destaco o sentido ritual, o de marcar distinçóes sociais e ideológicas no interior da cena, e o de constituir, junto a uma série de outros elementos, uma "identidade eletrônica", em oposição à "sociedade abrangente". Uma identidade que parece se definir ao mesmo tempo pela subversão da legitimidade do Estado na regulaçáo do consumo de substâncias - através de bricolagens práticas e cosmológicas contemporâneas - e dos próprios ideais libertários originalmente associados às festas rave, reproduzindo valores e práticas culturais dominantes.
\end{abstract}

palavras-chave Festas rave. Substâncias psicoativas. Identidade jovem.

Para analisar e compreender o sentido das práticas de consumo de substâncias na cena eletrônica ${ }^{1}$ sugiro que nos "inebriemos" um

1. "Cena eletrônica" é uma categoria originalmente nativa, negociada entre os produtores culturais e o público de "estabelecidos" (Elias 1990), que compartilham de códigos lingüísticos, estéticos, práticos e morais. $\mathrm{O}$ público da cena eletrônica é eventualmente disputado pouco deste mundo. Podemos começar com umas baforadas de diet $^{2}$ : as duas narrativas a seguir tratam de dois fatos relacionados ao uso de substâncias no contexto específico das festas de música eletrônica (raves). Apesar de se referirem a casos "limite", que não correspondem de modo algum a uma média e muito menos ao todo da diversidade de práticas de consumo de substâncias nas festas de música eletrônica, são bastante expressivas para iniciarmos uma discussão. Trata-se justamente de fatos extraordinários, revelando aspectos que de outra forma não se manifestariam.

O primeiro fato narrado ocorreu na festa da feira de "cultura alternativa" Mix Bazaar, em agosto de 2002. A feira realiza-se em finais de semana aproximadamente de dois em dois meses, e a festa sempre na noite de sábado para domingo. Nesta ocasiáo realizou-se no armazém B do Cais do Porto de Porto Alegre, de frente para o rio Guaíba. O segundo fato ocorreu na primeira edição em Porto Alegre da festa rave Exxxperience, em setembro de 2002, realizada exatamente no mesmo local da festa do Mix Bazaar.

por produtoras "outsiders" que tentam entrar neste mercado cultural. Define-se concretamente pelos espaços de sociabilidade reconhecidos, como festas rave, em clubs, pubs, feiras alternativas, grupos de discussão na internet, lojas de roupa, cursos de DJ.

2. "Diet" é uma substância cuja utilidade original, segundo os nativos, é a limpeza de piscinas. Nas festas de música eletrônica é utilizado como um inalante/ entorpecente de caráter "underground". 


\section{A transmutaçáo}

... eu fiquei sabendo que ele cheirava solvente ${ }^{3}$ em casa, em casa !!! ... e o cara, segundo o André, tinha contato com outras realidades,... falou que o solvente era a salvaçáo do mundo. ...não, e esse cara era como se fosse um filósofo, ele tinha vários conhecimentos, tudo adquirido através dos inalantes, tá ligado, ele recebia o conhecimento através da viagem do inalante... [...]

... uma estória engraçada desse cara, que numa festa lá, aquela lá do Mix Bazaar, o cara tomou um teto ${ }^{4}$ desse negócio, desse diet ai, ai embolotou 5 , ficou deitado, assim, e parou a festa assim em volta do cara, e ai daqui há pouco o cara pegou e se levantou dançando um break ${ }^{6}$ assim, toda festa começou a vibrar assim, a bater palma,... ai depois o cara veio me falar que ele tinha morrido e ressuscitado como mestre Lú, tá ligado, e o cara é conhecido como Gô, tá ligado, chamam ele de Gô, só que ele falou que a partir daquele momento ele tinha se tornado mestre Lú,... ai numa festa depois dessa que ele morreu. (Juliano. Entrevista, em 08/07/03)

\section{A transcendência}

... É, eu acho que o cara teve uma parada cerebral, por causa do inalante, no auge da festa, dançando, e cheirando aquele esquema, e eu não cheguei a ver, só sei que quando eu cheguei um amigo meu falou que viu um corpo sendo tirado, e depois se ligou que era o cara. [...] Náo, o cara,... eu acho que ele... é que eu não

3. Substância de uso doméstico e industrial utilizada para limpeza e/ou dissolução/solvência de tintas óleo.

4. Vertigem; rápida perda da consciência, geralmente acompanhada de um desmaio de curta duração.

5. "Embolotar", neste contexto, significa cair no chão desmaiado.

6. Break é a dança típica do movimento cultural jovem hip-hop, seus passos são inspirados em movimentos "robóticos". convivia muito com ele, eu encontrava com ele em festa... [...]

... quando eu cheguei em casa, assim, depois que eu soube que o cara morreu, no flyer ${ }^{7}$ da festa eu li assim: "prepare-se para fazer parte da história”, ai eu me apavorei !!!,... eu olhei e tinha um símbolo Oum assim [no flyer], ai dei mais uma olhada e tinha uma cabeça com umas mandalas, ligando os pontos energéticos da cabeça assim, ai... [...] Ah, eu, bah, me apavorei quando vi o flyer, tá ligado, e tive uma idéia desse desenho que parecia uns espermatozóides entrando num óvulo, tá ligado, ai deu toda uma viagem de nascimento, com o Oum, que é o som primordial, "você vai fazer parte da história", e esse cara foi um dos caras que mais abriu minha mente assim, em termos de visão de mundo, o cara tinha uma visão tri esclarecida do mundo, não era preso a conceitos, em nada assim, e uma mente tri aberta assim, então a morte desse cara, e lendo o negócio do flyer no dia que ele morreu, foi um negócio que bah, caiu minha casa, foi foda assim !!!. [...] Pior que eu não fiquei ruim, na hora eu fiquei normal, só que o negócio foi mais a longo prazo, vira e mexe eu me lembro assim, e é um negócio que eu não consigo aceitar muito, eu me lembro do cara nas festas, dançando, porque o cara chutava o balde ${ }^{8}$ assim, tipo, ele entrava em transe mesmo na festa, e eu nunca via o cara pra baixo, ele sempre tinha uma mensagem de otimismo, assim, e sempre pra cima, e depois o cara sumiu, do nada assim, bah, foi uma viagem. (Juliano. Entrevista, em 08/07/03)

Em relação a esta segunda narrativa, acrescento ainda a menção feita por Juliano de que Gô teria passado um dia em estado de grande felicidade, aumentada ainda mais no momento

7. Flyer é o panfleto de divulgação das festas de música eletrônica.

8. "Chutar o balde" significa não dar importância a determinada coisa em determinado momento. 

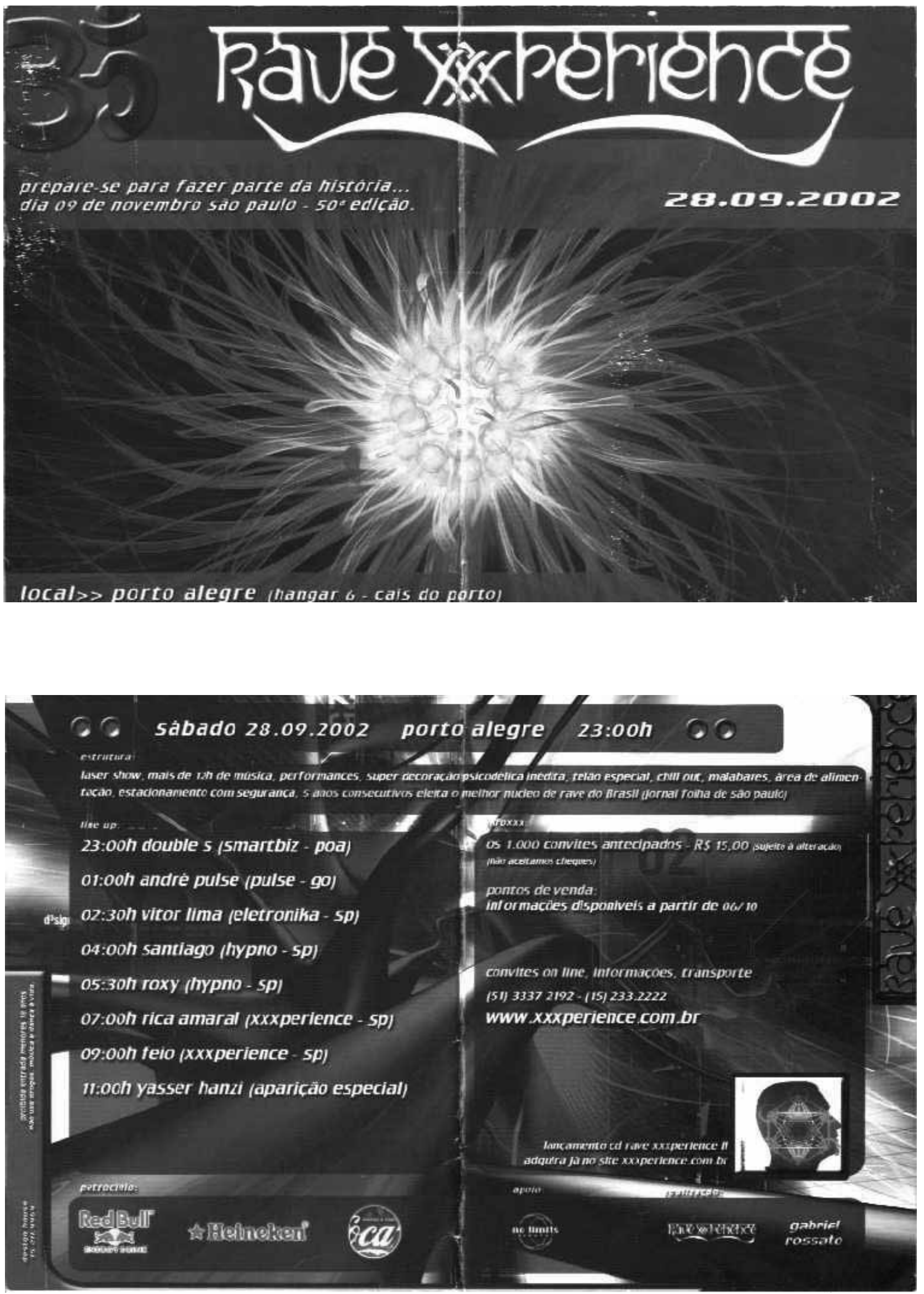
da festa. Há registros, inclusive, no $E-A r^{9}$, um antigo informativo eletrônico da cena de Porto Alegre, de que esta festa vinha sendo comentada entre o público local com dois meses de antecedência. Revelando uma certa extraordinariedade atribuída ao evento pelos ravers.

$\mathrm{Na}$ primeira parte da narrativa podemos destacar o caráter heurístico atribuído ao consumo do inalante, como forma de ampliar a percepção da realidade e aumentar o "conhecimento" sobre ela. Nota-se que o narrador atribui à sua personagem um status significativo: desempenharia a função de uma espécie de "guru" entre os participantes de sua rede de relações. Os "conhecimentos adquiridos através de suas viagens com solvente" parecem ter eficácia no convencimento dos participantes quanto ao seu poder intelectual no sentido de "compreensão do mundo".

$\mathrm{O}$ primeiro fato narrado, em que Go - sob efeito de inalante - desmaia, e em seguida, surpreende o público que se aglomerava em seu entorno para ajudá-lo, retomando a consciência e realizando movimentos associados pelo narrador aos dos dançarinos de break, é interpretado pelo próprio Gô como uma transformação repentina de si. Uma mudança de identidade própria de seres com poderes sobre-humanos, capazes de interferir diretamente sobre a ordem humana e natural, de ultrapassar o limiar da existência e retornar à condição comum com outra identidade, resultado de um ato de "revelação" ou "iluminação".

O segundo acontecimento, conforme narrado, conecta a ação da personagem Gô a dimensões mais abrangentes da especulação filosófica sobre a "existência humana": a "história", o "nascimento", o "som primordial do universo". Enfim, aspectos da mesma "grandiosidade" que os poderes previamente reconhecidos em Gô, concretizando-se na forma de uma trans-

9. E-Ar. Electronic Alternative Resistence no 48. Disponível em: <http://www.e-ar.cjb.net>. Acesso em: 16 ago. 2002. cendência espiritual no momento em que ele teria obtido o saber universal. A interpretação do evento, realizada por Juliano, a partir da leitura de símbolos que compunham o flyer de divulgação da festa, conecta uma série de elementos simbólicos disponíveis a partir de um esquema interpretativo bastante particular.

Estes elementos expressam, primeiro, uma crença na verdade e eficácia de sua interpretação para os fatos; e, segundo, um fenômeno global contemporâneo, muito comum entre jovens de classe média envolvidos com a música eletrônica. Fenômeno em que há uma bricolagem de práticas rituais e discursivas resultante da combinação de elementos originários de cosmologias religiosas orientais, de outras geraçóes de culturas jovens e da tecnologia utilizada na produção e ritualização da música eletrônica. Enfim, uma série de evidências que nos permitem caracterizar a cultura da música eletrônica dançante no campo mais amplo das culturas místico-alternativas, que foram descritas por Luis Eduardo Soares em "Religioso por natureza: cultura alternativa e misticismo religioso no Brasil" (1989).

Um dentre os vários aspectos destacados por Soares, que definiriam as culturas alternativas em geral, seria o da existência de condições de se efetivar o "acesso do ser humano aos segredos universais". Segundo ele, nos casos mais expressamente religiosos, as vias prioritárias de acesso ao conhecimento seriam os ensinamentos revelados e as experiências místicas, e, nos outros, a sensibilização receptiva da intuição. A "razão", nas culturas místico-alternativas, adequar-se-ia aos constrangimentos impostos pelas demais vias de acesso ao "conhecimento", limitando-se a apoiar e a traduzir o material apreendido pela via direta das "conexóes cósmicas" (Soares 1989: 194). No caso de Gô, os contatos que teria com "outras realidades" através das "viagens com inalante".

O acesso aos "segredos universais", no entanto, teria um caráter restrito - não é qualquer 
pessoa que o obtém -, o que resultaria do privilégio conferido à revelação, à participação mística ou à intuição receptiva frente a uma natureza que teria incorporado as propriedades do espírito humano (idem); como uma forma de legitimação de determinados papéis-sociaischave na organização interna das culturas alternativas ou religióes - e, por que não, na própria cena eletrônica -, e destas culturas e religióes frente à sociedade abrangente.

O fundamento deste privilégio da revelação ocorreria graças a uma "assimetria constitutiva” da relação a partir da qual se dá o acesso ao conhecimento. Haveria um "depositário de verdades", um "ser supremo", ou o próprio "cosmos", que, uma vez espiritualizado, assumiria a posição de sujeito, produtor de sentido, concebido como inteligência ampliada à plenitude do real. "Havendo irredutivelmente assimetria, sendo esta a condição de possibilidade do acesso (aos saberes universais) ${ }^{10}$, a limitação terá de ser reposta indefinidamente, para que o acontecimento continue sendo possível" (Soares 1989: 195).

Se não houvesse mais limitação, não haveria assimetria, e sequer a possibilidade de acesso humano às verdades universais, à inteligibilidade da essência do todo. A limitação de acesso ao conhecimento, no caso de Gô, teria sido a restrição da própria vida, depois de ter, conforme a interpretação de Juliano, alcançado a revelação plena. A sua morte corresponderia, no sentido de manutenção da assimetria, em uma forma de garantir a inacessibilidade comum ao conhecimento pleno. Gô morreu em função de sua transcendência a outra dimensão, porque descobriu o segredo da existência, sujeitandose às "leis" do conhecimento pleno.

Mesmo a situação extrema da revelação plena da verdade absoluta, em que a essência transparente

10. Parênteses inseridos por mim. como que divinizaria os homens com sua luminosidade fulgurante, mesmo nessa situação teria (sic) de estender, mais uma vez, a assimetria, pois suporia, ainda uma vez, a última revelação, aquela derradeira intuição que informaria o homem iluminado sobre o caráter último e completo de seu conhecimento. (Soares 1989: 195).

Como garantia de manutenção desta "assimetria constitutiva" do "conhecimento" nas culturas místico-alternatvas, Gô teria "entrado para a história”, conforme a conexão interpretativa realizada por Juliano entre o fato ocorrido na festa e a mensagem impressa no flyer, incorporando-se, a partir de um movimento definitivo de libertação do corpo, - que, como veremos, é um preceito componente da cosmologia da cena eletrônica -, ao plano cósmico. Os deuses, espíritos, ou forças místicas, onipotentes, oniscientes e onipresentes, geralmente habitam o céu ou são elementos da natureza, e não seres humanos que vivem entre nós.

Para reconstruir e compreender melhor seu sentido, muito mais das narrativas do que os fatos em si - o que seria uma tarefa muito mais complexa e delicada -, é preciso também ter acesso a alguns dos elementos que definem o que podemos chamar de "ideologia da transcendência” na cena eletrônica. Esta ideologia pode ser observada tanto nos discursos quanto nas práticas. A noção nativa de vibe é um elemento discursivo que podemos associar a esta ideologia. Chico, um participante assíduo de raves, procura sintetizá-la:

Vibe é a abreviação de vibração, seria tu conseguir pegar no éter que está causado, pegar no ar as ondas assim, de vibração da música, do ambiente, e conseguir entrar em sintonia, isso é a vibe. Se a vibe está boa é porque tem tipo, um inconsciente coletivo que tá conseguindo transmitir uma mensagem, mesmo que a gente náo consiga exprimir em palavras [...]. Muita 
energia, concentraçáo [...] tem que ter harmonia [...]. As pessoas têm que ter tudo isso, elas têm que estar em harmonia com a música, têm que estar em harmonia entre elas, têm que estar em harmonia consigo mesmas, tudo ao mesmo tempo, têm que estar com energia... (Entrevista, em 06/08/03)

A noção de vibe é freqüentemente usada para se referir à qualidade da festa, corresponde à emoção, à energia, à vibração e harmonia alcançadas quando os participantes do ritual de música eletrônica estão individual e coletivamente "sintonizados" com a música, entre si, e com o meio. Extasiados e transcendidos do "estado comum" físico, mental e espiritual, um estado que pode ser associado à communitas de Turner (1969) ou à "efervescência" de Durkheim (1913).

A “ideologia da transcendência”, a idéia de "ir além da condiçáo dada", tem, entretanto, seu sentido prático no "corpo" dos participantes. $\mathrm{O}$ propósito da música e do ambiente sensorial criado seria motivar a mobilidade corporal através da dança, que realizada até a exaustão física provoca a liberação de compostos neuroquímicos, que geram prazer. A idéia da estrutura da festa, tanto da dinâmica (diacrônica) quanto do meio ambiente sensorial (sincrônica), estaria diretamente relacionada à amplificação destas sensaçóes, pela indução de uma experiência "totalizante" de longa duração, que ultrapassa o limiar da noite, avançando muitas vezes por boa parte do dia seguinte. Assim, conforme esta lógica, as substâncias seriam consumidas para prover o corpo com mais energia, amplificando as sensaçóes naturalmente provocadas sem a sua utilização. Para que se possa "ir além", "transcender”, pelo transe hipnótico, libertando-se do ego e do superego, pela expansão da consciência ou da sensibilidade ao ambiente.

Em síntese, podemos dizer que o alcance da vibe dependeria de vários fatores. Sem uma ordem de importância: do ostinato da música, reforçado pelas luzes; do processo neuroquímico de liberação de substâncias presentes no corpo humano, em virtude do grande esforço físico realizado dançando-se na festa, e que provocam liberaçóes emocionais; do compartilhamento de um mesmo estado com uma grande quantidade de pessoas; do uso de substâncias que reforçam estes estados corporais; e, por fim, da crença na possibilidade de seu alcance, conforme a cosmologia presente na cena eletrônica, da qual a narrativa de Juliano é um exemplo.

Nesta conexáo da narrativa expressa por Juliano com a descrição genérica da cosmologia das culturas místico-alternativas feita por Soares, o consumo de substâncias parece adquirir um sentido cultural, senão para todos, pelo menos para os participantes "estabelecidos" (Elias 1990) da cena eletrônica. Estes promovem e têm incorporado uma sensibilidade cultural que inclui um ethos, uma visão de mundo e práticas que dão sentido ao ato de permanecerem dançando durante horas em ambientes escuros com luzes coloridas, sob o ostinado da música eletrônica em alto volume. A seguir, procuro situar as narrativas sobre o caso de Gô entre algumas questóes que parecem ser fundamentais para a análise das práticas de consumo de substâncias na cena.

\section{Uma pausa no êxtase}

Meu interesse se dirige aos sentidos simbólicos e práticos do consumo de substâncias como prática cultural jovem na cena eletrônica para a construção de identidades; muito mais que como um fim em si mesmo. Nesta direção, proponho-me reconstruir etnograficamente ${ }^{11} \mathrm{o}$

11. As informaçóes contidas neste texto são resultado do trabalho de campo realizado de agosto de 2002 a setembro de 2003 no universo social definido pela cena eletrônica de Porto Alegre. Observei, também, festas na cidade de São Paulo e arredores, no final de setembro de 2003, realizando algumas entrevistas com freqüentadores e produtores da cena paulistana. 
contexto de uso ritual, o discurso de sentido que o acompanha e os aspectos ideológicos e de distinção social, que de modo algum podem ser desprezados. Tais pontos revelam nuances no interior de um suposto "todo", como a cena eletrônica pode ser imaginada.

A substância MDMA, conhecida como ecstasy, tem sido tomada, principalmente pela mídia, como o "emblema químico" das cenas eletrônicas, a droga diretamente associada a elas. Isto é bastante evidente nas notícias de apreensão policiais de ecstasy e prisão de seus comerciantes. E mesmo os próprios efeitos do ecstasy são associados por alguns informantes como os mais compatíveis com o ambiente sensorial de uma festa rave. Um DJ compara, a partir de suas próprias experiências, os efeitos do LSD (ácido lisérgico) e os do ecstasy.

É que [o ecstasy] não é exatamente um estimulante, ele te faz sentir... tua parte sensorial fica mais aguçada, mas de uma maneira associada ao prazer. Por exemplo, é diferente do LSD, que tua parte sensorial também fica mais aguçada, mas não necessariamente está ligada ao prazer. Numa viagem de LSD, tu pode te dar conta de certas coisas que antes tu não estava te dando, ou pode ter... mexer em memórias tuas engavetadas, e tu vai estar ouvindo uma música, digamos, e tu vai estar ouvindo ela diferente,... mas o ecstasy, ele amplia tua audição, tua visão, e junto com isso vem... quase, não chega a ser uma euforia, mas tu fica, é como se tu ficasse com o instinto à flor da pele, digamos, então é muito mais fácil tu dançar, e ai toda aquela massa de gente... [...] Claro, mas é uma combinação, não é só a droga... é pela música em si, tu consegue sentir realmente mais a música, [...] e aquilo, e aquela massa de gente que está ali na pista... deixa de ser uma massa de gente e passa a ser quase uma comunhão, ... (DJ, em entrevista)

As observaçóes incluem as festas de música eletrônica tanto em clubs como raves, identificadas como pertencentes à cena eletrônica. Ver Fontanari (2003).
Há, no entanto, uma série de outras substâncias utilizadas que revelam uma diversidade sob esta suposta hegemonia do ecstasy. A visão do "ecstasy como emblema da cultura" certamente reduz a "diversidade química", e de significados sociais e culturais, a apenas um elemento. Mas como o ecstasy não é a única substância utilizada, a cena não é um todo coerente nem estático.

Neste sentido, é necessário evitar representá-la como um território homogêneo, sem diferenças internas de práticas ideológicas e sociológicas e de visão de mundo. Assim, a noção de "cena" - como um espaço geográfico permanentemente mutável de práticas e experiências de produção, apropriação e ressignificação simbólica de elementos culturais de origens locais e globais diversas, para a construção de identidades individuais e sociais locais, marcado por disputas internas por poder e prestígio no trabalho de agenciamento cultural e na definição das fronteiras simbólicas e físicas do território -, teria uma relevância epistemológica significativa para a apreensáo da diversidade e dinâmica das práticas culturais jovens na cena eletrônica. Da mesma forma, o conceito de "cena" também é importante para a superaçáo do conceito de cultura como algo unificado, homogêneo, rígido, essencializado, estático, conforme a sua crítica contemporânea que reivindica a consideraçáo das dimensões histórica e de poder, responsáveis pela historicização e fragmentação de seu caráter de todo coerente e imutável (Dirks, Eley \& Ortner 1994; Comaroff \& Comaroff 1992).

Mary Bucholtz (2002) parece adaptar de modo fecundo as discussóes teóricas mais amplas em relaçáo ao conceito de cultura às "culturas jovens", expressáo que ela propóe superar (pela mesma crítica mencionada acima) com o conceito de "práticas culturais" da juventude. A autora se preocupa em focar a "ação" dos jovens em termos de construção de suas identidades sociais no contexto contemporâneo. 
Nesta linha, as práticas de consumo de substâncias como ecstasy, diet, anfetaminas e outras, poderiam ser interpretadas como práticas culturais jovens visivelmente opostas a algumas estruturas de poder e instituiçóes sociais estabelecidas; e como tal deveriam ser compreendidas “[...] não simplesmente como manifestaçóes específicas de angústia pessoal, mas muito mais significativamente como práticas culturalmente críticas, através das quais os jovens exibem sua agência” (Bucholtz 2002: 531). Pensando o consumo destas substâncias no contexto ritual da música eletrônica como "fuga psicológica", ou como "prática socialmente desviante", estaríamos reduzindo-as e deixando escapar entre os dedos um modo particular da construçáo de identidades jovens individuais e coletivas no mundo contemporâneo.

O sentido do uso do conceito identidade jovem seria não "[...] evocar nem as conhecidas formulaçóes psicológicas de adolescência, como uma prolongada 'busca por identidade', nem o rígido e essencializado conceito que tem sido alvo da crítica recente. Mas pelo contrário, a identidade é ativa, flexível, e sempre-mutável, e não mais para a juventude que para qualquer geração.” (Bucholtz 2002: 532). O estudo das práticas culturais jovens, para Bucholtz, enfatiza o modo "aqui e agora" da experiência dos jovens, as práticas sociais e culturais a partir das quais constroem seus mundos (idem), considerando a emergência de identidades em novas formaçóes culturais que combinam criativamente elementos do capitalismo global, transnacionalismo e cultura local. (Bucholtz 2002: 525).

Deste modo, o que as representaçóes e o consumo de substâncias na cena nos diriam em termos de práticas culturais e construção de identidades jovens? Para responder esta questão, parto das que considero as principais dimensóes de sentido local para estas práticas: ritual, de distinção social e ideológica e de geração. Elas, no entanto, parecem chocar-se com a legitimidade reivindicada pelo Estado no controle do uso e comércio de substâncias consideradas ou náo perigosas, o que termina por lhes reservar tom subversivo. Parecem chocar-se também com o conceito de saúde promovido por agências do Estado e pelo capitalismo contemporâneo, mostrando que alguns grupos sociais subvertem-no na definição de suas identidades em alguns contextos específicos - como o da combinação entre lazer e religiosidade radicais, que parecem caracterizar esta experiência para o público insider da cena. E por fim parecem, por outro lado, substrato para a reproduçáo de valores e modelos dominantes que seriam supostamente opostos à ideologia originalmente associada a este tipo de festa. Todos estes aspectos expressam a dinâmica local do fenômeno global das festas rave.

\section{Um cenário para as narrativas - peque- no fragmento da "cena de Porto"}

Seja por puro acaso, ou não, eu estava presente nas duas festas mencionadas acima (as que foram cenário para os atos de Gô), fazendo observaçóes de campo. Ainda não havia conhecido Juliano, a não ser por me recordar de sua fisionomia em meio às milhares de pessoas que participavam da festa do Mix Bazaar: um rapaz de uns vinte e poucos anos, com uma barba enorme e com uma camiseta estampada com uma figura egípcia, fazendo gestos de reverência ao DJ. Ele estava na festa em que Gô sofreu um "teto" e na festa em que morreu. Eu também estava lá, mas náo vi nada. Uma festa rave ocorre num lugar de grandes dimensóes, ocupado por muitas pessoas, e por uma infinidade de microeventos significativos que ocorrem simultaneamente, dentre os quais conseguimos perceber e registrar uma porção limitada do que se encontra em nossos campos de percepção visual e sonoro, principalmente. Mesmo assim, sobram elementos para reconstruir o contexto do fato 
ao qual as narrativas apresentadas acima se referem ${ }^{12}$.

Pode-se entrar e sair de uma festa de música eletrônica sem perceber qualquer indício de consumo de substâncias ilícitas. A visibilidade deste tipo de consumo depende em grande parte das intenções do consumidor em se revelar ou não e da perspicácia na observação da prática de consumo em si ou de suas evidências. $\mathrm{O}$ estabelecimento de vínculos com os nativos nos permite, no entanto, superar metodologicamente estas limitaçôes.

Em setembro de 2002 fui à rave Xxxperien$c e$, junto com Roberto e Karina, antigos freqüentadores da cena local. Antes de chegar na festa, passando pela avenida Mauá, já podíamos escutar uma batida "surda", constante e muito potente, que vinha dos armazéns do Cais do Porto. Estacionamos o carro no pátio externo, pois dentro do pátio custava $\mathrm{R} \$ 10$. Comprei, por $\mathrm{R} \$ 20$, muito contrariado, o ingresso de um cambista, que ainda queria me cobrar $\mathrm{R} \$ 5$ pela vaga, mas não paguei. Fomos caminhando pelo pátio do Cais do Porto até a entrada da festa, em meio a outras pessoas que chegavam.

Chamava atençáo o perfil do público: jovens aparentemente de 18 a 30 anos, com suas roupas de estampas e cores exclusivas. Um estilo "esportivo estilizado", que parece definir a esté-

12. Quase como uma "sorte etnográfica”, depois de ter observado estas e mais uma série de festas em Porto Alegre e imediaçóes, registrando-as em meu diário de campo, tive oportunidade de conhecer Juliano, através de um colega que me convidou para um jantar em sua casa, para que me apresentasse uns amigos que iam às raves. Foi uma surpresa. Além de já tê-lo descrito em uma passagem de meu diário de campo como uma personagem emblemática da cena eletrôni$c a$, pude ser apresentado pessoalmente a ele, que ficou igualmente surpreso quando lhe revelei já ter escrito sobre ele em meu diário. Em seguida, apresentou-me uma série de relatos e interpretaçóes sobre eventos que já haviam sido etnografados por mim, dispondose a continuar contribuindo em minha pesquisa. tica visual desta juventude abastada, sendo complementado por corpos atléticos, preparados em academia, e enfeites, como correntes grossas no pescoço para os homens, cabelos bem tratados, brincos grandes e roupas sensuais para as mulheres. $\mathrm{O}$ estacionamento interno também, cheio de carros relativamente novos, alguns modelos importados como BMW e Mercedes remetiam à presença de uma juventude pertencente à elite econômica da cidade. Um segundo olhar, para além desta performance ostentatória notada à primeira vista, reparava em uma diversidade de público cujo despojamento de símbolos de poder de uma elite massificada revelava uma diversidade de estilos e identidades jovens, algumas vezes combinados: dark, punk, heavy metal, hippie, reggae, grunge, convencional.

O armazém 6 do Cais do Porto era um pavilhão grande, estava todo decorado. Nas paredes havia painéis de mais ou menos 1,5 x 2 metros, com temas "psicodélicos" pintados com tinta luminosa. No teto estavam penduradas oito lâmpadas grandes de luz negra, e também várias estruturas de canos de PVC envolvidas por redes de tecido luminoso: uma espécie de art decó psicodélica para festas rave. Havia um aroma agradável no ambiente, produzido por um incenso gigante preso numa das colunas de sustentação do prédio. Em um lado do pavilhão estava o DJ, num palco, tendo às suas costas um teláo, onde eram projetadas animaçóes e fractais produzidos em computador.

Do lado direito do DJ ficava o equipamento que produzia uma série de efeitos com feixes de luz, misturando as cores verde, amarelo e azul. Desde efeitos simples, como feixes de luz que em movimento cruzavam o ambiente, até uma "malha" de feixes que se fechava logo acima de nossas cabeças. Produzia também um túnel giratório e enfumaçado de cor verde, momento em que muitas pessoas emitiam gritos eufóricos. Tratava-se de um ambiente de caráter "onírico". Tudo isso abaixo de psytrance, a 
versão mais recente do estilo trance. Uma música com o andamento marcado por uma batida grave e "seca", a mais ou menos $140 \mathrm{BPMs}^{13}$, e por uma linha de baixo "monoton" quatro vezes mais rápida. Sobre esta base musical, são feitos efeitos sonoros "espaciais" e "psicodélicos", algumas vezes criando pequenas células melódicas. Algumas freqüências graves não eram escutadas, mas sentidas como vibraçóes no peito ou mesmo na superfície da pele. Apesar de um tanto agressivo, o apelo sensorial do ambiente era muito forte e contagiante.

A notícia que tive depois da festa foi que o público chegou a 6 mil pessoas. Tanto o interior do pavilhão, quanto a parte ao ar livre com vista para o rio, estavam cheios de gente. Para se deslocar era preciso caminhar desviando-se e pedindo licença. Chegar próximo ao palco do DJ era quase uma luta: passar no meio da multidão que dançava em espaços exíguos, ombro a ombro, numa disputa pelos melhores lugares garantidos à base de sutis empurróes e leves cotoveladas. Era difícil acreditar como alguém conseguiria se sentir à vontade para dançar nestas condiçóes; mas muitos pareciam não se importar. Havia também a opção de espaços livres próximos à outra extremidade do pavilhão. Pessoas paradas: só do lado de fora, descansando, bebendo e conversando.

Quanto às substâncias consumidas, não havia maiores evidências além dos legalmente aceitos cerveja, água, cigarro e energy drink. Pelo menos até às 05:30h da manhá, hora em que fomos embora com a festa ainda em alta - Karina mais uma vez exagerou no vinho -, ainda estava escuro no pavilhão. Mesmo olhando à minha volta, nada havia me chamado a atenção. Neste momento da festa, conforme fiquei sabendo posteriormente através de Juliano, Gô já teria transcendido.

13. Batimentos por minuto.

\section{A importância das classificaçóes}

Gilberto Velho chama atenção para a importância da "classificação" em relação aos "tóxicos", objeto de conflito entre a visão dos utilizadores e a dos órgãos de comunicação de massa e entidades oficiais, que marcam intensamente de forma diferenciadora as pessoas que os utilizam com categorias como, por exemplo, a de "viciado" (Velho 1998:13). Esta posição expressa, de certo modo, a visáo da sociedade abrangente sobre o consumo de substâncias psicoativas como algo anormal ou transgressor, e, especialmente em relação às cenas eletrônicas, justifica açóes de repressão, como algumas vezes tem-se observado sobre as festas de música eletrônica e seus freqüentadores.

Ao tratarmos de tal tema, coloca-se como obrigatória a desconstrução antropológica da categoria "droga", e de outras categorias simbolicamente negativizadas no modo como são utilizadas em nossa sociedade. Este empreendimento é, sem dúvida, problemático, pois relaciona ao mesmo tempo questôes morais e técnicas, categorias éticas e êmicas. A definição do que é e do que não é "droga” é, antes de tudo, uma questão de "classificação", permeada pelo "poder" de definir o que faz e o que náo faz bem para o corpo, o que é e o que não é permitido ${ }^{14}$.

Há uma série de substâncias utilizadas no cotidiano, algumas legitimamente recomendadas e cujo uso é visto como exclusivamente positivo tal como os remédios, que são drogas usadas para curar infortúnios físicos e/ou mentais. Há outras também, cuja composição química exerce influência sobre a disposição mental, sensorial e física dos seres humanos, em graus variados, consideradas ou não drogas, algumas mais identitariamente marcadas, outras não,

14. Uma discussão mais aprofundada certamente seguiria na direção das formulaçóes de Foucault sobre os dispositivos de disciplinamento do corpo. Ver Foucault (1975; 1976). 
como o café, o amendoim, o tabaco, o guaraná, a coca-cola, os chás, o chimarrão, e os produtos derivados e processados a partir dos princípios ativos destas substâncias. Estas, porém, não têm a mesma carga simbólica negativa que outras, como o ecstasy, o LSD, a cocaína, a maconha, o ópio, etc. consideradas absolutamente ilícitas.

O modo como todas estas substâncias são classificadas, porém, depende de como se constituem as relaçóes de poder em cada contexto. Isto é, de quem as consome, de quem as recomenda, com que finalidade sáo usadas, em que quantidade, em que lugar, da presença ou não dos olhos do Estado etc. Assim, sua classificação como legais ou ilegais depende da legitimidade atribuída a determinados grupos sociais para classificar o que é e o que não é legal.

Dentre uma série de termos acadêmicos, técnicos e utilizados pelo senso comum, como "drogas" - sejam legais, ilegais, naturais, seminaturais, sintéticas; "substâncias" psicoativas e psicotrópicas; "tóxicos"; "narcóticos"; e "entorpecentes", parece não haver unanimidade quanto ao mais adequado, muito menos para o discurso antropológico. Tendo em vista este problema, utilizo apenas o termo "substância", reconhecendo seu caráter genérico e nada diferenciador de outras substâncias de caráter predominantemente nutritivo, como os alimentos e refrigerantes, e de hidratação, como a água. Sua definição, porém, corresponde ao contexto em que a emprego: o da cena eletrônica. As "substâncias" da cena.

A vantagem do termo "substâncias" seria a de se apresentar como uma alternativa ideologicamente neutra em relação ao senso comum e, da mesma forma, em relação ao impasse entre os termos técnicos. Gilberto Velho (1998) utiliza o termo "tóxicos", argumentando que esta é a palavra usada pelo grupo por ele estudado, na zona sul do Rio de Janeiro. O termo refere-se basicamente à maconha, cocaína, heroína, ácido, ópio, haxixe, e certos remédios, em sua totalidade, substâncias consideradas de venda e porte ilegal. Há uma série de termos nativos, como bala e " $e$ ", para o ecstasy; doce para LSD, entre outros, mas nenhum termo que os designe genericamente, como o termo ético "substâncias".

\section{Distinção social, mainstream e un- derground}

O consumo de substâncias, assim como a indumentária e os adereços usados pelos participantes da cena, os cortes de cabelo, as viagens e o conhecimento de outras cenas nacionais e internacionais, o desempenho de funçóes de visibilidade na cena, a proximidade de pessoas de destaque; tudo isso faz parte do que Sarah Thornton chama de "capital subcultural" (1995: 11) dos participantes da club culture. Capital subcultural é uma noção inspirada nos conceitos de "campo" e "capital" de Bourdieu, porém, adaptados pela autora ao contexto das "subculturas" (Hebdige 1979) jovens. As diferenças de posse de capital subcultural expressariam formas de distinção social operadas no interior da cena eletrônica que conformariam uma hierarquia de prestígio, estabelecida pela diferença de capital subcultural específico da cena.

O ecstasy seria o exemplo de uma substância de caráter mainstream; é a substância de maior prestígio na cena eletrônica. O diet, e outros tipos de inalantes underground, como a cola de sapateiro, o loló, o cheirinho do morro, pelo contrário, seriam de menor prestígio. Durante as $18 \mathrm{~h}$ de duração da excursão que saiu de Porto Alegre para o festival Skolbeats de 2003 em São Paulo, composta quase que exclusivamente por freqüentadores assíduos da cena, entre as conversas que se desenrolavam era comum escutar relatos sobre experiências com ecstasy, e "viagens de ácido (LSD)", mas absolutamente nenhum sobre viagens de diet, cola de sapateiro ou loló. Já a maconha, de uso táo comum, só seria vista como algo extraordinário por quem não compartilhasse em 
nada dos códigos desta subcultura, alguém com um "capital subcultural" muito baixo.

Os modos de afirmação das identidades underground e mainstream na cena, como se pode observar, dão-se em uma dinâmica de oposiçóes relacionais. Se as substâncias underground são desprezadas pelos consumidores de ecstasy e de outros elementos de prestígio, devido ao seu baixo grau de distinção; seus consumidores e os locais que estes freqüentam também o são. Seus clubs e festas preferidas, para os "mainstream", seriam "sujos", "baratos", onde entra "qualquer um”. Em contrapartida, o público "mainstream" abastado é igualmente desprezado pelo público underground por "não ir nas festas por causa da música, e sim para 'badalar", por "querer aparecer", enfim, de "deturpar" o sentido da música e da festa em função de práticas e valores pertencentes justamente ao mundo ao qual a ideologia underground se opóe.

Apesar do perfil do público da cena se definir entre os limites do que se pode chamar de camadas médias, há uma variação considerável dentro destes limites, expressa de algum modo nos tipos ideais underground e mainstream de práticas e significados. $\mathrm{O}$ poder aquisitivo pode ser um limitador do tipo de substância a ser utilizada, no entanto, restringindo-nos à dimensão econômica, estaríamos adotando uma posição "materialista" e desconsiderando a dimensão cultural intrínseca a estas práticas. As motivações são simbólicas, e o conceito de “ajustamentos" (Goffman 1961) nos permite captar a nuance das práticas.

Poderíamos definir o significado social e cultural destas substâncias a partir do conceito de capital subcultural de Thornton, e é a partir desta lógica que tais substâncias operam como elementos de distinçáo e identidade de "classe" na cena. Esta lógica opera de um modo muito semelhante ao princípio lévi-straussiano, segundo o qual a substância é escolhida pelo seu significado simbólico entre a série de substâncias disponíveis. Tal como expresso em Lévi-Strauss (1962), identifica-se a lógica de construção de identidades sociais; neste caso uma relação entre uma "série humana" e uma "série de substâncias", cada uma com um significado e um lugar na hierarquia de prestígio, em termos de capital subcultural na escala de valores da cena.

No entanto, como as motivaçóes para estas práticas são simbólicas e operadas por indivíduos em diferentes contextos, estes significados e formas de distinção podem ser por eles subvertidos. O preço das substâncias, deste modo, seria um delimitador bastante relativo para o seu consumo, considerando a possibilidade de uma série de "ajustamentos" que flexibilizam a limitação econômica de acesso elas. Renata, outra antiga freqüentadora, revelou-me ter já tomado um ecstasy ganho de um amigo. Juliano, embora tenha tomado LSD já algumas vezes, nunca teve de adquiri-lo, sempre ganhou de algum amigo que comprava em grande quantidade. Os relatos de "ganhar" substâncias nas festas não são raros. A prática de compartilhamento de substâncias é bastante comum, como é o caso dos inalantes, bebidas, cigarros, ou mesmo comprimidos. A possibilidade de ajustamentos não altera, no entanto, o prestígio de algumas substâncias, que se reflete de algum modo em seu preço.

Nos bares internos das festas uma lata de $355 \mathrm{ml}$ de cerveja varia entre de $\mathrm{R} \$ 2,50$ a $\mathrm{R} \$$ 5,00 . Uma dose de uísque ou vodca de $\mathrm{R} \$ 5,00$ a $\mathrm{R} \$ 8,00$. A variedade de bebidas depende do tipo de festa. Até hoje não observei venda de vinho em nenhuma festa ou casa noturna exclusivamente de música eletrônica. Uma prática isolada é a do casal Roberto e Karina, que acompanhei algumas vezes. $\mathrm{Na}$ rave Xxxperience mencionada, entre o caminho e a espera para entrar na festa, os dois tomaram todo o conteúdo de uma garrafa de dois litros de vinho. Beber vinho ou outros tipos de bebida "no gargalo", 
na entrada das festas, seria, neste contexto, uma prática de caráter underground entre o público das raves. Roberto e Karina tomavam vinho antes de entrar como forma de reduzir os custos com bebidas. $\mathrm{O}$ custo do vinho ainda era dividido entre os interessados, e seu tipo preferido, o vinho doce, não passava de $\mathrm{R} \$ 4,00$ reais o litro. Grande parte dos freqüentadores de festas de música eletrônica náo enfrenta o problema de ter de economizar dinheiro, enquanto outros economizam dinheiro para entrar nas festas e muitas vezes adotam táticas para entrar de graça, evitando o preço do ingresso, que, dependendo da festa, varia de $\mathrm{R} \$ 8,00$ a $\mathrm{R} \$ 30,00^{15}$.

Uma carteira de cigarro não passa de $\mathrm{R} \$$ 5,00. Um frasco de energético varia de $\mathrm{R} \$ 7,00$ a R\$ 10,00. Algumas substâncias podem ser compradas "muito camufladamente" de pessoas que ficam no interior das festas, outras devem ser adquiridas por seus consumidores de outras maneiras, principalmente através de traficantes em lugares estrategicamente situados na cidade. Certa vez Karina me informou ter pago R\$ 25,00 por uma cartela de anfetaminas, conseguida através de uma amiga que trabalhava em uma farmácia. Um comprimido de ecstasy varia entre R \$ 40,00 e R\$ 50,00. Uma “unidade" de LSD custa em torno de $\mathrm{R} \$ 30,00$. A grama de maconha, equivalente a um cigarro, custa $\mathrm{R} \$$ 1,00 . Um frasco de lança-perfume era vendido nas raves do carnaval de 2002 na Guarda do Embaú, em Santa Catarina, por R\$35,00. Um frasco pequeno de diet pode, eventualmente, ser comprado em uma festa por $\mathrm{R} \$ 10,00$. O preço das substâncias, no entanto, varia não só conforme o seu grau de refinamento, se legal ou ilegal, mas também de um lugar para outro, tornando-se geralmente mais caras pela facilidade de aquisição.

Algumas substâncias podem ter inclusive versóes artesanais mais baratas, como é o caso

15. Preços de 2004. do lança-perfume. Entre a multidáo que se juntava no portão de entrada do festival Skolbeats de 2003 em São Paulo, um raver da excursão de Porto Alegre comprou de alguns garotos, por $\mathrm{R} \$ 20,00,200 \mathrm{ml}$ de "lança-perfume" em um frasco branco, bastante diferenciado do original transparente de tampa verde. Garotos na rave Earth dance em Santos/SP, em setembro de 2003, inalavam "lança-perfume" em latas vazias de cerveja, depois de dividirem um "coquetel" cujo nome não sabiam informar, mas o qual, segundo eles, era feito com vodca, suco de abacaxi e uma cartela de "remédios", derretida.

Qual seria a motivação para a sujeição ao risco de ingestão de substâncias de efeito tão imprevisível sobre o corpo e táo negativamente previsível para o conceito dominante de "saúde"? Isso parece náo ser levado muito em conta pelos consumidores de substâncias underground, nem pelos consumidores de substâncias de maior prestígio social na hierarquia de valores da cena. Visto que, de acordo com a sua ideologia dominante, a noção de "indivíduo" que rege as relaçóes entre as camadas médias no cotidiano é subvertida em função da "sociedade", da "comunidade" em êxtase no momento da festa, para o que deve se "entregar", conforme o que parece ser o sentido dominante do fenômeno rave como um todo: o de entregar-se para a música e libertar-se do ego. O "risco" envolvido neste consumo parece ser parte, justamente, do modo de afirmação de identidade neste contexto, tem uma base de sustentação cosmológica, uma lógica social de distinção, e uma "antilógica" de ajustamentos.

A opçáo pelo consumo de determinada substância é acima de tudo um modo de afirmação de identidade, tanto no interior da cena eletrônica quanto em oposição ao mundo externo. São os jovens que "consomem" estas substâncias como forma de afirmação de suas identidades, e não "são consumidos" por elas. É necessário resgatar sua "agência” cultural, seu 
caráter ativo como sujeitos, como enfatiza $\mathrm{Bu}-$ choltz (2002).

\section{Agenciamento jovem}

A identidade de geração, além da cosmologia e da distinção social, também parece ter algum peso para a compreensão do sentido do consumo das substâncias na cena. Kristina Sliavaite, autora de uma etnografia sobre a cena eletrônica de Vilna, capital da Lituânia, apresenta relatos de informantes que opunham o uso de drogas nas raves ao uso do álcool pelas geraçóes mais velhas; utilizado, de acordo com seus informantes, para a obtenção de um prazer de curta duração, pois seus usuários bebem e em seguida vão para a cama, dormir. O álcool é oposto às drogas consumidas nas raves, porque essas proveriam energia por muito mais tempo. Um dos sentidos que a autora identifica para o uso de substâncias é o de expressão do conflito entre geraçóes, bastante marcado na Lituânia, mas também de identidade e experiência histórica, neste país que, em virtude da barreira de informaçóes, até o fim da União Soviética não teria tido contato com qualquer elemento da "cultura da música eletrônica de pista", tendo suas primeiras raves organizadas em 1994 (Sliavaite 1998).

O exemplo dado por Sliavaite nos permite entender melhor como esta identidade é constituída em termos geracionais, em Porto Alegre, cidade cuja forte presença do rock, e de seu estilo de vida correspondente, como forma de identificação entre camadas médias, são espelhados no discurso dos DJs de música eletrônica.

... a gente tá revolucionando a música assim como o rock revolucionou os anos 50 , no final dos anos 40, 50, a gente tá nesse estágio assim.

(DJ Double S. Entrevista, em 21/11/02)

... a música eletrônica não é só música, é comportamento, é muita coisa envolvida né, cara, é procura pelo bem estar... [...] a música eletrônica é meio que uma coisa que veio pra ficar, como teve a era do rock'n'roll... (DJ Fabrício Peçanha. Entrevista, em 08/07/03)

O consumo de substâncias, deste modo, é contextualizado como marca de geração etária na sociedade. Consumir diet ou ecstasy é uma forma de afirmar uma identidade náo só nas hierarquias de prestígio no "interior" da cena eletrônica, mas também como um paradigma de identidade jovem, que apresenta tanto rupturas quanto continuidades em relação ao paradigma dominante, historicamente anterior, nesta localidade. A este "novo" paradigma, que vai além dos modos particulares de expressão identitária no interior da cena e os transcende, podemos chamar de "identidade eletrônica", nome metafórico para a identidade jovem construída pela participaçáo e compartilhamento dos valores e práticas da cena eletrônica. A transcendência destas diferenças se daria justamente em sua dimensão ritual, pelo compartilhamento da experiência descrita anteriormente, tal como Juliano enfatiza. O que importa é entrar em transe:

... não interessa se tá no estilo ou não,... não interessa se o cara é um punk ou se o cara é um clubber, tá ligado, não interessa se o cara é um mauricinho ou se o cara é um maloqueiro da vila, interessa o nível de transe, tá ligado, e esse nível de transe da galera não é um negócio que tu vê, tu sente,... então quanto maior o número de pessoas que se deixar largar assim, pelo pensamento, e ficar só no som, maior vai ser a energia da festa. (Juliano. Entrevista, em 08/07/03)

$\mathrm{O}$ que ambas tendências, underground $\mathrm{e}$ mainstream, compartilhariam é o ritual da festa. Cada indivíduo, tendo incorporado a sensibilidade cultural da cena eletrônica, definindo-se identitariamente a partir da dialética entre sua condiçáo social e a ideologia que adota, teria um 
modo próprio de alcançar a libertaçáo do ego em função da música e do ambiente sensorial.

É, no entanto, precisamente no aspecto ritual que parece se situar o principal apelo da cena no processo de agenciamento jovem. Isto é, a estratégia através da qual os seus produtores buscam agregar cada vez mais participantes a seu mercado cultural, compondo a partir deste tipo de experiência a sua singularidade como identidade de geração, um estilo de vida "novo" para a "juventude" do presente.

\section{Os perigos políticos da "libertaçáo"}

A disposição corporal cotidiana, isto é, o controle do corpo, justamente o objeto de agenciamento desta identidade, parece ser o principal campo de disputas entre a cultura da música eletrônica dançante, e sua contrapartida repressiva, o Estado. Mary Douglas (1970), analisando o fenômeno do transe, destaca a "consonância entre níveis de experiência" em uma mesma sociedade, entre, por exemplo, o controle corporal e a formalização das instituiçôes, para justificar a ocorrência do transe em sociedades cujas instituiçóes sociais sáo menos formalizadas. Neste sentido, a idéia de transe e libertação do corpo existente na cena eletrônica iria de encontro às disposiçóes corporais das sociedades modernas, subvertendo a cultura dominante, só que a partir de seu interior, considerando a condição de inclusão social em que se encontram os jovens participantes da cena.

Para Douglas, o corpo humano é visto não apenas como uma metáfora da cosmologia social, mas como a suposta origem das categorias culturais, do sistema simbólico que ordena as relaçóes sociais e todo o universo (Douglas 1970: 89). Subverter as categorias convencionalmente associadas ao corpo seria, deste modo, subverter automaticamente a própria cultura, pois o corpo é a cultura. Fazer isso por meio de música repetitiva em experiências sonoras totalizantes, motivadas pelo consumo de substâncias cuja legitimidade de prescrição é reivindicada pelo Estado - que se reserva o direito do controle sobre o corpo de seus contribuintes -, parece ser, à primeira vista, o principal motivo pelo qual os órgãos oficiais, em algumas circunstâncias, têm se empenhado em reprimir e controlar as festas de música eletrônica e as substâncias nelas utilizadas.

Quanto maior o grau de formalização das instituiçóes de uma sociedade, maior parece ser o grau de repressão. Inúmeras são as notícias de monitoramento de raves, fechamento de festas, e tratamento violento dos participantes, incluindo prisóes e agressão física, na Europa, EUA, e outras partes "civilizadas" do mundo. Neste sentido, dançar música eletrônica passa a adquirir um caráter político, pois tal ato passa a ser visto pelo Estado como um ato de subversão da legalidade e dos conceitos que definem as atividades de lazer.

No Brasil, apesar de alguns incidentes de ação violenta da polícia, como o cancelamento de algumas festas no Rio de Janeiro, a proibição de raves em Santa Catarina, revistas e constrangimentos impostos aos participantes, e algumas prisóes e apreensóes de ecstasy em diversas partes do país, a política de repressão parece, no entanto, incomparável à repressão policial em outros lugares. Lugares em que a existência das raves depende de que sua organização e divulgação se dêem de modo camuflado para despistar as autoridades. A asserção de Mary Douglas quanto à correspondência entre a formalizaçáo das instituiçóes sociais e a formalização do uso do corpo, e supostamente um correspondente grau de repressão a práticas que se contraponham a esta formalização, parece, no entanto, ter algum sentido. As autoridades, ao menos, parecem cumprir o seu papel para provar esta teoria.

Embora a grande maioria das festas realizadas no Brasil dependa de autorização para a sua realização (o que é fornecido), por serem realizadas 
em lugares de visibilidade, e também por seus organizadores temerem comprometer a sua mar$\mathrm{ca} /$ nome e investimento sob a ameaça de uma intervenção policial que encerre a festa, elas parecem continuar como espaços de "transcendência”. Em Porto Alegre, as raves de maior destaque são divulgadas em outdoors e na mídia de grande alcance, algumas sendo inclusive patrocinadas por grandes empresas, como é o caso das companhias de telefonia celular, as principais patrocinadoras de raves e festas de música eletrônica em geral. Um freqüentador "underground" certamente veria este fato com pesar, contabilizando o aumento do preço do ingresso, e o aumento de um público "nada a ver" com a coisa, além de uma perda de "aura" devido à excessiva plasticidade do evento. No entanto, é justamente neste tipo de evento que a qualidade de som e luz são melhores, em que há um investimento também em DJs mais famosos. Os patrocínios de grandes empresas também envolvem marcas de grande valor no mercado e poder econômico, dando assim uma aparência sóbria ao evento e afastando a possibilidade de intervençóes policiais, deixando livres aqueles que querem "ir além".

O caso das raves francesas talvez nos permita estranhar melhor o seu significado no Brasil. $\mathrm{O}$ pesquisador francês Emmanuel Grynzpan (1999) diferencia dois tipos de festas, as "freeparties", gratuitas e clandestinas, realizadas em lugares distantes dos centros urbanos; e as "comerciais", legais, autorizadas pelo poder público e incorporadas à lógica do consumo. A base desta diferença para ele está na transgressividade e subversão do modelo dominante de sociedade ocidental, realizadas através do uso de drogas, da "insegurança" dos lugares de realização - desconhecidos das autoridades -, do desrespeito à legislação da autoria, da "economia paralela", do nomadismo e marginalidade.

Para Guillaume Kosmicki (2001), outro estudioso das raves, no final da década de 1990 já não haveria mais festas "freeparty" na França com a utopia que animou o início do movimento. Para ele, em virtude de sua difusão e "popularização", este tipo de festa teria se degradado e perdido o sentido, incorporando aspectos que combatia, como a diferenciação social e a hierarquização, e também indivíduos agressivos e violentos, contrários à ideologia PLUR (Peace, Love, Unit and Respect), definida como um valor universal das raves. De um espaço de "inversão", passou a "imitar" modelos sociais convencionais.

O processo de difusão das raves no Brasil, entretanto, ocorreu de modo bastante diferente. As primeiras raves já teriam começado como festas de caráter comercial, trazidas como um produto cultural empacotado, uma novidade vinda direto dos centros geopolíticos de poder. Este é o exemplo das L\&M Party, patrocinadas e utilizadas na divulgação desta marca de cigarros, tidas por consenso na cena brasileira como as primeiras raves do Brasil, realizadas em 1993 em Porto Alegre, São Paulo e Curitiba - experiências míticas para os que puderam participar. Mesmo assim, com seu caráter histórico comercial, as raves no Brasil não deixam de se apresentar como lugar para diversos modos de experiência, sendo ou não foco de repressão policial. Entre tais experiências está o consumo de substâncias underground em um universo predominantemente mainstream. Além disso, continuam sendo espaços para experiências e interpretaçóes místico-filosóficas que se potencializam inclusive em contraste com os modos legalmente subversivos, mas caretas, de utilizar o momento de inversão que é a festa, para a reafirmação de sua posição de classe através dos mesmos mecanismos de diferenciação evocados à luz do dia.

\section{Voltando da festa}

O consumo de substâncias neste universo, um tanto em evidência, das raves revela lógicas e sentidos aplicáveis a outros universos, muito diferentes de uma festa rave. Seu sentido, como pretendi 
mostrar, não se dá pelos efeitos fenomenológicos da substância em si ou sobre a experiência pessoal do indivíduo como ser isolado. Tampouco por questóes de desequilíbrio emocional ou fuga psicológica, tal como o discurso do senso comum sobre o consumo de substâncias poderia interpretar. $\mathrm{O}$ consumo de substâncias nas festas rave tem um significado social e cultural definido no contexto em que é utilizado, por práticas e concepçóes compartilhadas e voltadas a fins específicos. É inclusive fortemente determinado por estas lógicas sociais e culturais, da mesma forma que o são as açóes de repressão a este tipo de festa e a caça às drogas promovida pelo Estado.

É esta perseguição que politiza o consumo das substâncias, atribuindo-lhe um caráter subversivo que não está em sua natureza, contribuindo inclusive com o seu poder sedutor. Neste sentido são "hidden transcripts" (Scott 1995), práticas de resistência que ocorrem nos interstícios do poder, no escuro, e muitas vezes restritas ao domínio interior do indivíduo, sem deixarem registros e sem terem visibilidade, embora tenham conseqüências concretas para as estruturas que as contêm. O risco envolvido na transgressão contribui certamente com seu significado cultural e social, criando barreiras que incrementam o desejo de transgredir, enfrentar a ordem e ir além de onde é permitido. De visitar lugares "exclusivos", guardados pela lei, de onde muitas vezes não há volta - como no caso de Gô.

Em oposiçáo ao mundo moderno, branco, masculino, careta, e ocidental que tem nos conceitos de indivíduo e corpo cristáos a sua base de sustentação, a festa rave parece apresentar conceitos diferenciados, que incluem uma música e uma dança, mas também uma cosmologia de sentidos, elementos técnicos e químicos para a sua objetivação. Se estes parecem subversores da ordem, há de se lembrar que são, no entanto, performatizados justamente no momento socialmente liminar da festa, em que a ordem se apresenta, por definição, já suspensa. Mesmo assim, em algumas de suas interpretaçóes locais, terminam por ser reapropriados em modos que náo são mais do que a reproduçáo dos modelos dominantes em sua versão local. Seja pelo fetichismo em relação ao exótico que vem dos centros de poder como novidade tecnológica, seja pelos modos de distinção social empregados pela elite e grupos de camadas médias como forma de marcar simbolicamente seu poder local. Ou ainda, pela própria reprodução do sistema capitalista no desenvolvimento do mercado do entretenimento, que incrementa e torna a festa do final de semana algo mais extraordinário, sofisticado e mais caro do que poderia ser.

Termino com a pergunta: não estaríamos justamente desenvolvendo modos liminares e criativos - adequados aos grupos sociais que deles se utilizam, às suas novas construçôes cosmológicas, à tecnologia disponível e à química disponível - para nos adequarmos mais estreitamente ao cotidiano ordinário sem festa, à ordem oficial, dominante, capitalista, supostamente subvertida na transcendência da pista de dança? Não seria esta justamente a razáo da tensão entre os "recursos para ir além" e a "mecânica do juízo"?

\section{Resources to go beyond and judg- ment mechanic: on the comsuption of illegal substances as a cultural action by the youth in electronic music parties}

abstract The purpose of this article is to analyze and interpret the consumption of substances commonly known as "psycho-actives", "psychotropics", "toxic", or "narcotic", in the environment of electronic dance music parties (raves), as cultural practices fulfilled by middle-class youths, departing from ethnographical fieldwork in the electronic dance music scene of Porto Alegre/BR. Objectifying the distance from the common sense about these substances, I seek through ethnographic depiction to rebuild some senses related to them by the natives in the local 
context of symbolic appropriation and consumption. Among these senses I underline the ritual one, the social and ideological distinctions within the scene, and the way to build an "electronic identity" as opposed to an "inclosing society". That identity seems to be locally defined through a paradoxical subversion of both State official regulations for substances consumption, and the libertarian ideals of first raves through the reproduction of dominant values and cultural practices.

keywords Rave parties. Psychoactive substances. Youth identity.

\section{Referências bibliográficas}

BBUCHOLTZ, Mary. 2002. "Youth and cultural practice". In: Annual Review of Anthropology. 31: 525-552. Disponível em: <http://anthro.annualreviews.org>.

COMAROFF, John; COMAROFF, Jean. 1992. "Ethnography and the historical imagination”. In: Ethnography and historical imagination. Boulder: Westview Press.

DIRKS, Nicholas; ELEY, Georff; ORTNER, Sherry. (orgs.), 1994. "Introduction". In: Culture/Power/History: a reader in contemporary social theory. Princeton: Princeton University Press.

DOUGLAS, Mary. 1970. “Los dos cuerpos”. In: Simbolos naturales: exploraciones en cosmologia. Madrid: Alianza Editorial.

DURKHEIM, Émile. [1913]. As formas elementares de vida religiosa. São Paulo: Martins Fontes, 1996.

ELIAS, Norbert. [1990]. Os estabelecidos e os outsiders. Rio de Janeiro: Jorge Zahar, 2000.

FONTANARI, Ivan Paolo de Paris. 2003. Rave à margem do Guaiba: música e identidade jovem na cena eletrônica de Porto Alegre. Dissertação de Mestrado. Porto Alegre: PPGAS/ UFRGS. Disponível em: <http://www.biblioteca.ufrgs. br/bibliotecadigital/2004-1/tese-csh-0403210.pdfs.

FOUCAULT, Michel. [1975]. Vigiar e punir. Petrópolis: Vozes, 1987.

\section{autor Ivan Paolo de Paris Fontanari}

Doutorando em Antropologia Social / UFRGS

Recebido em 31/01/2006

Aceito para publicação em 11/11/2006
[1976] Historia da sexualidade (I). Rio de Janeiro: Edições Graal, 1988.

GOFFMAN, Erving. [1961]. Manicômios prisóes e conventos. São Paulo: Perspectiva, 2001.

GRYNSZPAN, Emmanuel. 1999. "Fête du bruit". Sociétés, 65: 69-84, 1999/3.

HEBDIGE, Dick. [1979]. Subculture: the meanings of style. London and New York: Routledge, 1994.

KOSMICKI, Guillaume. 2001. "Le sens musical en freeparty aujourd'hui: entre idéologie et utopie”. Sociétés, 72: 35-44, 2001/2.

LÉVI-STRAUSS. Claude. [1962]. O totemismo hoje, tradução de M. B. Corrie. São Paulo: Abril Cultural, coleção Os Pensadores, 1980.

SCOTT, James. 1985. Weapons of the weak: every day forms of peasant resistence. New Haven and London: Yale University Press.

SLIAVAITE, Kristina. 1998. When global becomes local: rave culture in Lithuania. Avd. För Socialantropologi. Sociologiska Institutionen, Lund Universitet. Disponível em: <http://www.anthrobase.com/txt/S/Sliavaite_K_01.htm>. Acesso em: 13 ago. 2004.

SOARES, Luis Eduardo. [1989]. "Religioso por natureza: cultura alternativa e misticismo ecológico no Brasil”. In: $O$ rigor da indisciplina. Rio de Janeiro: RelumeDumará, 1994.

TURNER, Victor. [1969]. O processo ritual. Petrópolis: Vozes, 1974.

VELHO, Gilberto. 1998. Nobres e Anjos. Um Estudo de Tóxicos e Hierarquia. Rio de Janeiro: Fundação Getúlio Vargas Editora.

\section{Nota}

Uma versão deste artigo foi apresentada no XVIII Encontro Anual da ANPOCS, Caxambu, 26 a 30 de outubro de 2004, seminário temático "Linguagens, sensibilidades, corporalidades: culturas jovens urbanas e novas configurações subjetivas". 